\title{
Promoting personal agency and social inclusion through the Clemente Australia Program
}

\author{
John O'Gorman \\ Griffith University \\ Jude Butcher \\ Australian Catholic University \\ Peter Howard \\ Australian Catholic University
}

\begin{abstract}
A program pioneered by Earl Shorris in New York for educating the poor and marginalised in the humanities has been employed successfully in Australia under the title Clemente Australia for promoting both personal agency and social inclusion. Personal agency and social inclusion are ever present goals for societies and communities but they are particularly relevant today, at a time of increasing number of people who are unemployed, homeless, refugees or are experiencing multiple disadvantage. Students and staff involved in the program have reported upon student self improvements which are indicators of enhanced personal agency and social inclusion. A number of rationales have been advanced for these successes of the program, ranging from empowerment and engagement to changing habitus. The paper, drawing upon social cognitive theory, presents an integrative rationale and framework explaining the development of personal agency and social inclusion promoted by the program and expressed in their becoming "political", engaged with people at every level of society. In terms of this integrative rationale, Clemente Australia builds ideas of hope, meaning, and identity into the personal narratives of participants through reflection on their personal and vicarious experiences in the program and the competencies and changed expectancies that these bring. This integrative view can illuminate participants' reports of the program and suggest ways of making it more effective.
\end{abstract}

Keywords: Clemente Australia, personal agency, social inclusion, social cognitive theory 


\section{Introduction}

Education is considered by those on both progressive and conservative sides of politics to be a means of overcoming poverty and social disadvantage. Education is also seen by many as being an important way of promoting social inclusion. The traditional view is that education is an 'escalator', developing the capabilities and the social relationships, the human and social capital (Becker, 1964; Coleman, 1988), necessary to improve life chances. On the other hand, advocates of critical pedagogy see education as a means for making the disadvantaged conscious of their oppression by the privileged and powerful, and with this raised consciousness comes action for social justice (e.g., Apple, 1995; Giroux \& McLaren, 1989). Although the traditional and radical approaches can be considered poles apart, Endres (2002) argued that there is common ground between them, if traditional approaches are not simply limited to those that promote cultural transmission or that concentrate on basic skills and vocational training. He cites in this regard the work of Shorris (2000) who proposed that poverty can be addressed by making people more 'political' through reflection on the major questions about life originating with the Greek philosophers. The Clemente program, initiated by Shorris in the mould of traditional liberal education, seeks to provide those in poverty with the means to break "the surround of force" that keeps them there.

The Clemente program began in New York in 1997 at the Roberto Clemente Family Guidance Center in Manhattan using a curriculum modelled on that Shorris had studied under Robert Hutchins at the University of Chicago. Hutchins helped found the Great Books program that emphasised the western liberal arts tradition and eschewed narrow specialisation (Barker, 2006). The program is currently sponsored by Bard College in New York City, but variants of it have been established in a number of American states and Canada. It began in Australia in 2003 as a joint initiative of Australian Catholic University (ACU) and the St Vincent de Paul Society in East Sydney. In 2005, ACU and Mission Australia initiated a collaborative process to establish a second Sydney-based program titled 'Catalyst' to be offered at the Mission Australia Centre. Clemente Australia, as the program is termed in Australia, is now offered in all Australian capital cities and three regional cities, in partnership with 15 community agencies, universities, corporate partners, and local councils.

Clemente Australia is relevant to attempts to increase equity and participation in Australian higher education (see e.g., Centre for the Study of Higher Education, 2008) and more broadly to the Australian Government's initiatives to promote a socially inclusive society (see e.g., Hayes, Gray, \& Edwards, 2008). According to the Government's social inclusion website, these initiatives recognise that 'many Australians are excluded from the opportunities they need to create the life they want, and can become trapped in spirals of disadvantage caused by family circumstances, low expectations, community poverty, a lack of suitable and affordable housing, illness or discrimination - often leading to leaving school early, long-term unemployment and chronic ill-health. Some people are at greater risk of multiple disadvantages, such as jobless families, Aboriginal and Torres Strait Islander people, people with disability and 
mental illness, vulnerable new migrants and refugees, those with low incomes and people experiencing homelessness' (http://www.socialinclusion.gov.au/about/whatsocial-inclusion). The Government's social inclusion strategy involves policies and programs directed to 'supporting individuals and communities to work their way to a better life' through participation in education and training, increasing employment opportunities, fostering community connectedness, and increasing choice. The groups to which the strategy is directed and its key aims are entirely consistent with the ideas informing Clemente Australia.

The present paper briefly describes Clemente Australia and its reported effects on participants, reviews the accounts of the principles at work in the program, before advancing an integrated model of the program that can aid participants, staff, and observers to understand it better and that can guide research and development of it. The model is based on social cognitive theory and proposes the ways in which agency and connectedness are promoted in the program.

\section{The Clemente Australia Program}

Modelled on Shorris's Clemente program, Clemente Australia has some features particular to itself. It combines university-level education with social support in community settings to cater for the particular needs of disadvantaged people. It uses studies in the Arts and Humanities, such as subjects in literature, drama, history, and ethics to build participants' self-esteem, create a feeling of community engagement, and develop new possibilities for the future. The units of study are of 12 weeks duration and are university-approved. Successful completion of four units leads to a non-award qualification that can be used for entry to a standard university undergraduate program at participating universities.

Students typically attend a two-hour lecture and a two-hour 'shared learning' tutorial session each week. The lectures are taken by university staff selected on the basis of their scholarship in the areas of study being taught, and their willingness to work with homeless people in a community setting. The 'shared learning' sessions are staffed by volunteers from the business and corporate sectors, known as 'learning partners'. The emphasis is on both partners, student and volunteer tutor, learning from their interaction. Learning partners are briefed prior to commencement of the courses on their role in assisting students to complete their assignments and other coursework, particularly with regard to computing and written language skills. To further coordinate the ongoing implementation of the program each site has a community-based coordinator who responds to the social support needs of students, liaises with the university academic coordinator in managing the everyday issues related to the program, and oversees the weekly lecturing and learning partner sessions.

Although initially offered only off campus, now some elements of Clemente Australia such as the learning partner sessions are held on university campuses where 
there is better access to computing, technological support and resources such as those available through the University library.

From the outset, formal assessment has been considered important to identify the program for students as an educational rather than a welfare program.This, however, has presented a challenge in that timely completion of assessment items and at the standard required can seem to be at odds with differences in participants' learning styles and differences in the pace at which different students develop competence This has been managed in a number of ways, one being grading the difficulty of assessment tasks throughout the semester, using short reflection papers prior to a major assessment item (Broadbent, 2008). Reflective practice is a structured component of the reviews of the sessions, whether scheduled classes or learning partner sessions, and provides conversational opportunities for students to conceptualise and synthesise their thoughts and ideas (Howard et al. 2008). Such purposeful reflection enables them to share their life experiences with others and to locate their thinking in personal context.

Features of the program considered important for its effectiveness are: delivery in an environment with which students are familiar and where they feel comfortable; small classes (generally 8-15); humanities education (acting as a challenge to students to reflect on society); rigorous university level education; lecturers with a flexible and engaging methods of teaching and communicating; learning partners who are part of the learning journey; ongoing availability of a 'welfare worker' who supports students' noneducational needs and to whom learning partners and the lecturer can turn for support; administration and technical support, including access to computing and other necessary resources (Mission Australia, 2007).

Since 2003, 852 students have enrolled in the program run by ACU and its partners. Table 1 summarises progress statistics by site.

Table 1

Progress statistics by site for the period 2003 to 2012

\begin{tabular}{rrrrrrrr}
\hline Site & & \\
\hline Ballarat & Brisbane & $\begin{array}{c}\text { Campbell } \\
\text { town } \\
(2008-)\end{array}$ & Canberra & Melbourne & Newcastle & Surry Hills \\
& $(2007-)$ & $(2007-)$ & $(2007-)$ & $(2008-)$ & $(2009-10)$ & $(2003-)$ \\
74 & 72 & 125 & 107 & 113 & 41 & 320 \\
9 & 10 & 15 & 5 & 9 & 5 & 22 \\
1 & 2 & 4 & 0 & 2 & 0 & 6
\end{tabular}

Note: Cell entries are numbers of students. Years for sites are those for which the program

operated. 'Completed' are numbers of students at each site completing all four units of the Certificate of

Liberal Studies. That is, students completing one, two, or three units are not counted.

'Further study' are numbers enrolling at ACU only. 
Students are selected, on the basis of interviews, in terms of adequate levels of intellectual and personal functioning, as well as commitment to tertiary-level education. In practice, this means that they must be able to read a newspaper and have a settled place of residence. They are mostly single, separated or divorced, many with children or dependants. More than half have lived in crisis or emergency accommodation or on the streets and most have a long-standing physical or mental health condition, illness, or disability. Most have attended primary or secondary school and most are recipients of a government pension of some sort. The only age limit on students is that they need to be 18 years of age or older.

Surveys, focus groups, and structured and unstructured interviews have been used since 2003 to gauge the impact of the program (Howard et al., 2008; Yashin-Shaw, Howard, \& Butcher, 2005). The primary reasons students enrol include motivation to better themselves, to prove they have the ability to achieve, to move on from where they are, or to gain additional skills. For most students, their circumstances have meant that university study has not been an option for them in the past, either because they did not have the necessary entry qualifications, or because they lacked the confidence to tackle what they saw as an intimidating challenge.

In terms of personal agency and social inclusion students of the program have reported improvements in self esteem, confidence, and capacity to cope with serious difficulties; desire for increased social participation and a feeling that they are part of a local community; improved relationships with others, including family and friends; a valuing of learning and the opportunity to learn from others (e.g., Howard et al., 2008). These outcomes are similar to those reported in an evaluation of the original Clemente program (Shorris, 1997a). Examples of these outcomes in the words of two students with the fictitious names of John and Jess are presented in Figures 1 and 2. 
John came to Clemente after losing his job, wife, and access to his son through drug addiction. After five years as an unemployed addict, a rehabilitation program helped him overcome his dependency and he looked for a way back to mainstream society. At his mother's suggestion, he sought out the Clemente program in Canberra and has now graduated and is back in employment (part-time). Extracts from his comments follow:

"We study legitimate university subjects, one per semester, and it's a very supportive and non-judgemental environment. ...It provides structure to my life ...You meet some interesting people. ..It increases your self-esteem. Each week you are going to a real university, studying a real subject, doing real assignments. This definitely starts to improve your confidence; you start to feel like you're more than just a bum. ...the subjects we study are all very interesting...It increases your chance of employment. ...Through doing the course you start to meet people...And you start to build up a network of people who know you and who know your abilities. And that's important! Because everybody does have some skills and abilities...And it's through a program like Clemente that people start to gain some confidence in their skills...And it's through the network of people l've met at Clement that things have started to really turn around for me....l've gone through the Clemente program with a core group of seven or eight students. We are of different ages, different backgrounds, and are all addressing different issues. Whether it be drug and alcohol addiction, sexual abuse, or mental health issues, we are all doing our best to overcome these difficulties and rebuild our lives. We all desperately wish to rejoin mainstream society."

Figure 1. Extract from John's experience of Clemente Australia. 
Jess is an Aboriginal single mother of four young children, the oldest of whom is eight, and is expecting her fifth. While she has good memories of school she mainly found it boring and left after Year 10. Jess lives in public housing, is on Government benefit, and helps out at the school. She has a number of health issues. The following are extracts from her interview comments:

"I look forward to coming here every week... when I don't come it gets me a bit down. It's really homely and friendly. The atmosphere and meeting with everybody every week and it's just really nice to get out of the house and do something like for me and having the friends I've made here. Oh I haven't studied in 10 years. I didn't expect to do very well. But it's pretty easy once you put your mind to it and you get the reassurance from the lecturers and the peers in the class. Learning how to communicate with people better. Learning not to shut down and be quiet, that my opinion is valid. I'm more outgoing now I think. My kids, my father is proud of me for what I'm doing. My mum is. Before I just used to stay home all the time and now I'm actually getting out there and doing something and I'm enjoying it and just my outlook on life is different and I'm more happy within myself. It's made my whole life a lot better. I don't have a 'can't do' attitude no more, I have 'I can do it'. I've got friends now and I've got a better network of people that I can go and have a cup of tea and just vent to I guess. I look forward to coming here every Monday and Wednesday. Just sitting down and having lunch and having our little talks I guess. I love it and everybody gets involved. It's made my parenting skills a lot better, the way I deal with stuff is a lot better. It's broadened my outlook on life and I think everybody should be entitled to it. It's really made my life change... and the people that work with it are really devoted to helping us. I want to be an Aboriginal worker through the school...If I can reach at least one child in their life and inspire them to do something l'd be really happy."

Figure 2. Extract from Jess's experience of Clemente Australia.

\section{Understanding Clemente Australia}

Shorris (2000), in developing the original program, was concerned with overcoming disadvantage and promoting social inclusion among those who called themselves poor. He argued (Shorris, 2000, pp. 98-99) that "There are many paths out of poverty...No one can release the poor from poverty, no one can accomplish power for them". The rationale for the program, as Shorris advanced it, was that study of the humanities leads to reflection by students on their own humanity and that in turn develops a political life in students that enables them to 'burst out of their bonds' and engage with society and its members.

Numerous forces--hunger, isolation, illness, landlords, police, abuse, neighbors, drugs, criminals, and racism, among many others--exert themselves on the poor 
at all times and enclose them, making up a 'surround of force' from which, it seems, they cannot escape. I had come to understand that this was what kept the poor from being political and that the absence of politics in their lives was what kept them poor. I don't mean 'political' in the sense of voting in an election but in the way Thucydides used the word: to mean activity with other people at every level, from the family to the neighborhood to the broader community to the city-state (Shorris 1997b, p. 50).

According to this rationale Clemente Australia works by politicising students in the sense that it assists them to take up citizenship in the community from which they were previously estranged.

Central to the process described by Shorris is reflection, which is prompted in humanities programs by the questions that thinkers throughout the centuries have put to themselves and their fellows. As DeCoker (2002, p. 92) put it: "The questions the Clemente Course poses, as set out by Kant, expand and sharpen a student's mind: 'What can I know? How shall I live? What may I hope? And what is man?" Shorris provided instances in his description of the program of students not being able to sleep because of the questions raised in the course were running through their heads.

The idea of reflection is given further emphasis by Stevenson, Yashin-Shaw, and Howard (2007) who argued that changes induced by the Clemente Australia program could be understood in terms of conceptions of habitus.

The idea of habitus is used extensively by Bourdieu $(1990,1991)$ and previously by Mauss (1934) to refer to enduring socialised embodied thoughts, perceptions and actions... Substantial change in habitus would require being re-born and resocialised from birth. With such a fully deterministic reading of Bourdieu, there would be no point in the Clemente project as such a fundamental change is not possible for homeless people undertaking a few university courses. The more modest aim of the Clemente program is to move the participants away from reacting simply to contexts and events, i.e. seeking to interrupt the direct operation of the habitus, their automatic 'schemes', challenging the participants to resist their history-based anticipations about the results of present actions. Presumably, over time, such repeated experiences of critical thinking would lead to some changes in the schemes themselves, as new personal histories become embodied (p. 5).

Related to concepts of reflection and citizenship is that of empowerment. Studying the humanities through courses such as philosophy and ethics engages and empowers people to think about and reflect on the world in which they live. If they do this then they are less likely to simply react to contexts and events and more likely, themselves, to examine, question and contemplate. By doing so people can engage in "activity with other people at every level" (Shorris, 2000, p. 127). Thus studying 
humanities can help homeless people to become engaged 'public citizens' (YashinShaw et al., 2005, p. 2). The term 'empowerment' has been widely used in describing community programs and has on analysis been found to have several meanings. Perkins and Zimmerman (1995, p. 570) in introducing a series of papers on the topic pointed to the variety of definitions authors of the collection employed but went on to propose that:

The various definitions are generally consistent with empowerment as 'an intentional ongoing process centred in the local community, involving mutual respect, critical reflection, caring, and group participation, through which people lacking an equal share of valued resources gain greater access to and control over those resources' (Cornell Empowerment Group, 1989) or simply a process by which people gain control over their lives, democratic participation in the life of their community (Rappaport, 1987), and a critical understanding of their environment (Zimmerman et al., 1992).

Elsewhere the idea of engagement is stressed to a greater degree than empowerment in explaining the effects of the program.

One might say that the primary 'leap of faith' embedded in the Clemente and Catalyst programs is that the students' intellectual engagement with university education will lead to broader engagement with social institutions and with the community. In other words, the theory of change underlying Clemente and Catalyst states that tertiary-level humanities education can change the level of engagement of homeless people (Egan et al., 2006, p. 11).

Engagement, as with empowerment, is a widely used term in describing processes of social change, as Egan et al. noted. For these authors, engagement was "the process of establishing trust in the broader community" (p. 5).

The concept of social exclusion has entered the discussion of homelessness and disadvantage in the U.K., Europe, and Australia, and those involved in Clemente Australia have considered the program in these terms.

Catalyst-Clemente... is based on the belief that poverty is more than just exclusion from material goods - it's also about social exclusion. Accordingly, the way out of poverty is about giving people access to more than just a wage or vocational training, it's also about engaging them in activities that lead to social interaction, learning and community participation (Mission Australia, 2007, p. 1 ).

A further rationale is that based on the idea that education has a broad impact on the societies that promote it, beyond the cognitive or practical skills that are often the focus of individual programs. "Catalyst-Clemente Australia", according to Howard et al. 
(2008, p. 483), "stands as an alternative to the forms of education traditionally provided, in Australia, to marginalised people" (Egan et al., 2006). Usually vocational or 'life skills' courses are offered to disadvantaged people, with the aim of fostering employability, independent living, and self-management skills. However, education can provide more than vocational skills: education can enlighten, empower and fulfil (Hammond, 2004). Education is a key factor that ensures "individuals are endowed with capabilities that allow them freedom to choose to live their lives in ways that have real meaning and real value" (Henry, 2007, p. 8). Although vocational courses are important, it is equally important that the full potential of education to transform the lives of people be realised (Stevenson et al., 2007).

Hammond (2004, p. 553) argued that education

can lead to improved wellbeing, increased efficacy, protection and recovery from mental health difficulties, and more effective coping, including coping with physical ill health.

These 'softer' outcomes of education, as Hammond termed them, combine with the 'harder' outcomes of qualifications, employment, and career advancement to increase social engagement and civic participation. Drawing on Hammond's work, Howard et al. (2008, p. 4) proposed that education through Clemente Australia has a positive impact by promoting "self-esteem and self-efficacy, sense of identity, sense of purpose and hope, competencies and communication skills, social integration". Related to this is the rationale espoused by Bard College, a sponsor of the program in the United States: The program

is based on the belief that by studying the_humanities those who are economically and educationally disadvantaged can acquire the cultural knowledge and_conceptual skills necessary to improve their personal and societal situations (http://clemente.bard.edu/about/)

An important addition to theorising about the effects of Clemente-Catalyst was the proposal of Howard, Butcher, and Egan (2010) that Clemente Australia recruited hope and a sense of personal agency in participants. Drawing on Snyder's (1995; Snyder et al., 2000) theory of hope, they argued that key to the success of the program was

the development within marginalised people of a sense of their own agency to set goals; and a belief in their ability to choose pathways that will help them achieve those goals (p. 3).

They identified 'pathways thinking' as "one's ability to identify or generate the routes that lead to one's goal." Agency thinking, on the other hand, was defined as "one's ability to motivate oneself to follow these routes successfully." The two ways of thinking operate 
to reinforce each other such that, "Those who possess high levels of both pathways and agency thinking are said to be high in hope". The success of Clemente in these terms is based in the encouragement and the structure it provides for pathways and agency thinking which give rise to hope.

As this review indicates, common to most accounts of Clemente Australia to date is the fostering of personal agency, the capacity to effect change in oneself and one's circumstances through personal effort and enhance their sense of social inclusion. On the face of it, this may seem to adopt a social approach to agency and to open the way to victim blaming for those who do not benefit from the program: If the effectiveness of the program depends on personal characteristics, then failure must be a consequence of some personal shortcoming. However, the approach to human agency adopted by the social cognitive theorists, notably Bandura $(1987,2006)$, is that thought and action are a consequence of reciprocal relations between the person, their situation (importantly their social situation), and what they do in that situation. People act on situations and events but, according to social cognitive theory, are in turn influenced by them in terms of the opportunities or constraints they provide, the feedback they receive from their actions, and the interpretations they make of their own behaviour.

\section{A Proposed Framework}

Concepts developed by social cognitive theorists can be used to provide an understanding of Clemente Australia in terms of personal agency. An agentic analysis of the program begins by identifying its principal features. Liberal education, such as offered in degrees in the Arts and Humanities, is directed to meaning and value through exposure of students to literature, history, philosophy, and related subjects. Through this vicarious experience of other people's lives and ways of thinking, students can gain insight into themselves and the human condition. Courses of this sort are not typically didactic in style but allow for the negotiation of meaning by student and teacher and by students with each other. Group participation through tutorials and seminars is commonly an important element, which can broaden a student's social networks and provide the opportunity for informational and, at times, affective support from others. In some instances student involvement can build a sense of identity among a group passing through the same types of formative experiences. Although 'student centred', courses in the liberal arts require completion of assignments, such as essay writing, that are marked against standards of achievement that in turn provide students with feedback on what they have accomplished.

What a program of this sort provides then is:

1. A situation with rich possibilities for new learning and chance encounters that is at the same time supportive and minimally threatening.

2. Personal exposure to the situation in such a way that new behaviour can occur both directly and vicariously and can be reflected on by significant others in their environment as well as the person himself or herself. 
3. Sufficient time for new behaviours and ways of thinking to be initiated, practiced, maintained, and so become habitual.

It is within such an environment that it becomes possible for behaviour and cognition to change in ways that have continuing effects on personal perceptions and social circumstances.

Bandura proposed three processes as of central importance in promoting human agency: self efficacy, goal setting, and outcome expectations (see e.g., Bandura, 1977; 1991). Self-efficacy according to Bandura is the belief that one can perform a particular action, a belief about one's capacity. Beliefs of this sort are distinguished from outcome expectancies, that is, beliefs that certain actions will lead to particular outcomes. One is a belief about self and the other is a belief about one's environment. For example, a student may believe that it is very likely that hard work will lead to a good grade in a course they are undertaking (an outcome expectancy) but consider there is little likelihood that they will be able to undertake the hours of study necessary (an efficacy expectancy). Observations of what has happened for fellow students in the past and of their own attempts to study give rise to these different sorts of expectancies. Although both are important, efficacy expectations strongly influence what tasks are undertaken in the first place, how long effort is maintained in the face of failure, and when action will be terminated.

The third process is goal setting, which has attracted a considerable literature in its own right (see Locke \& Latham, 1990). Goals are cognitions about outcomes that may occur in the future. They are usually arranged hierarchically, with proximal goals leading to longer term goals that will bring about a desired course of action. Arranged in this way, goals provide a continuous source of self-motivation, with achievement of smaller, manageable steps maintaining pursuit of more significant outcomes, which require time for their achievement (Wood \& Bandura, 1989).

The three processes are related to each other, as the adaptation of the model by Lent, Brown, and Hackett (1994) summarised in Figure 3 makes clear. Self-efficacy expectations and outcome expectancies both influence goal setting and performance. Those high in self-efficacy with respect to a particular behaviour and those with expectancies that the environment will reward successful behaviour of this sort will set more specific and more challenging goals and will benefit more from feedback about the outcome of goal setting. Past experience gives rise to efficacy and outcome expectations which in turn influence the setting of goals and performance, with goal setting itself having a direct influence on performance. Omitted from the figure are feedback loops from performance to experience that show that successful or unsuccessful performance becomes part of the person's past experience which subsequently influences efficacy and outcome expectations. 


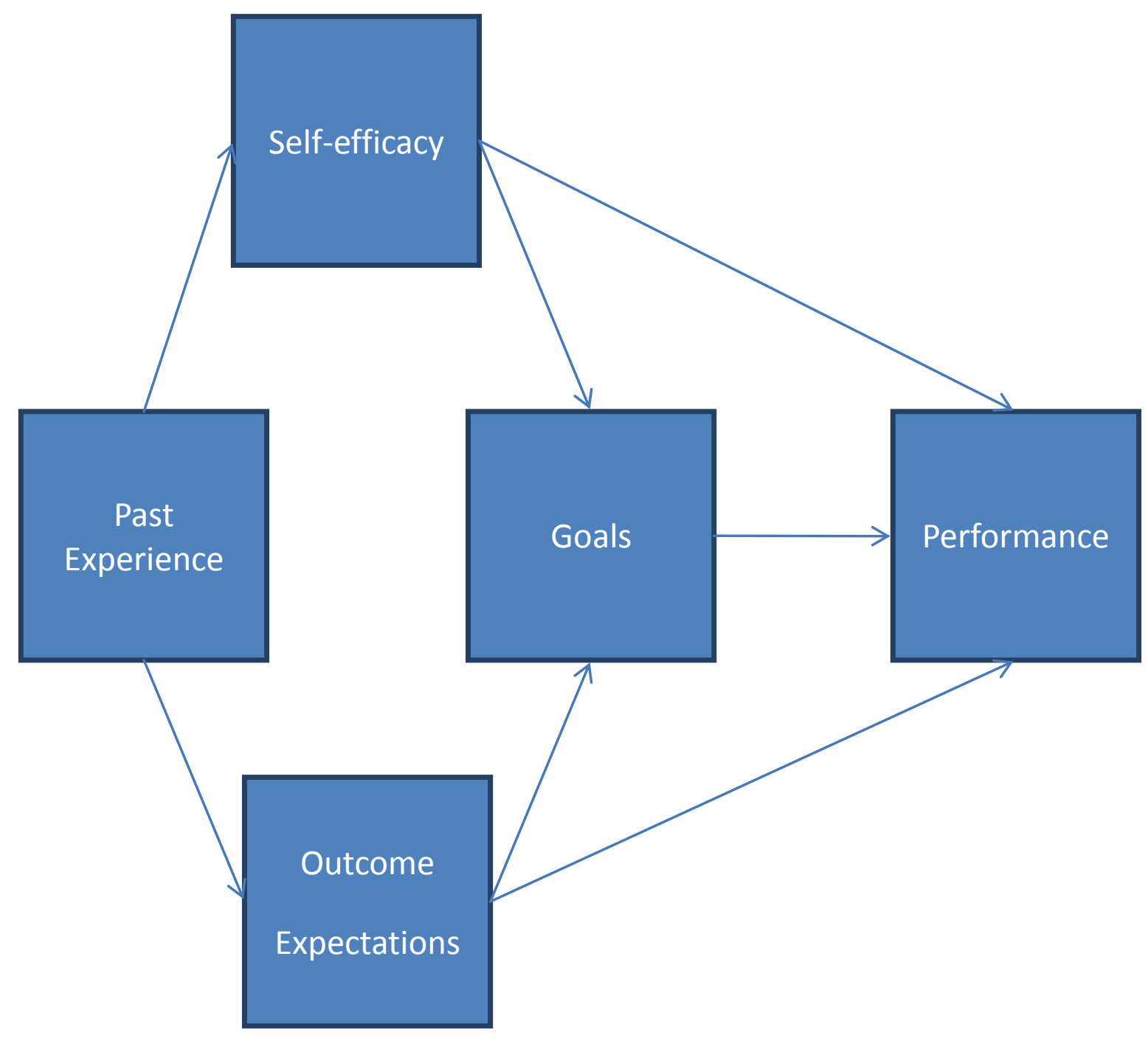

Figure 3. The interaction of expectations, goals, and performance in social cognitive theory (adapted from Lent et al., 1994).

The model outlines a process that is common to both advantaged and disadvantaged participants but the nature of past experience will differ between the two and this has influences on the other terms in the model. The past experience of disadvantaged people might be expected to provide little basis for personal belief in their efficacy and limited or unrealistic outcome expectancies. These in turn will lead to poor or little goal setting and subsequent poor performance. Past experience needs to be overcome and more positive expectations put in place. According to social cognitive theory this can happen through new experiences of success, either directly or vicariously. A challenging but supportive environment involving others like oneself provides opportunities for these to develop and with them successful behavioural outcomes. 
The change process occurs over time and different variables take on varying importance through the temporal cycle. Rothman, Baldwin, and Hertel (2004), for example, argued that in the early stages of behaviour change, self-efficacy expectations have a greater weight than outcome expectancies, because they determine whether the behaviour will be attempted and how realistic any goal setting will be. Once underway, the rewards and costs involved will have a major role to play, the former positively and the latter negatively, and efficacy and outcome expectations will assume lesser importance. In the further stage of maintenance of change, re-appraisal of the value of the new way of behaving may become critical. If the new way does not bring the outcomes it was expected to, then behaviour change will not be maintained. If it does, action becomes habitual without deliberation and previous behaviour becomes the best predictor of its future occurrence.

In these terms, participants entering Clemente Australia have their expectations reshaped by their experiences in the program. Initially, low expectations of success or of capacity to perform in the academic setting of Clemente Australia, based on past experience, are reformulated as some level of success is found in the new and relatively challenging but supportive environment. The 'success' may be as apparently small as being there on the first day or returning for the second, but these 'small' successes are built on as more successes follow with staff and learning partners supporting efforts at mastery.

The joint effects of efficacy and outcome expectations affect not only goal setting and performance but emotional state as well. Bandura proposed that the combination of high and low expectations of the two sorts produce varying states that are commonly labelled apathy and depression. Where both efficacy and outcome expectancies are high, a sense of confidence accompanies performance. High efficacy expectations coupled with low outcome expectancies lead to heightened arousal expressed in resentment, because the environment does not reward behaviors which the person has a strong belief they can perform. Where both efficacy and outcome expectancies are low, a state of apathy prevails as the person believes that they cannot perform the behaviour in question and that there would be no favourable outcome even if they could. Where self-efficacy is low and outcome expectancies high, the accompanying state is akin to depression because the person believes they cannot perform an action that, if they could, would lead to reward.

Again because of previous experience as a disadvantaged or marginalised member of society, apathy, depression, or resentment may be commonly felt emotions among beginning participants in Clemente Australia and may be sufficiently strong for some to prevent their attendance in the first place. Managing these emotions, as well as the anxiety provoked by a challenging new environment, calls for the development of strategies of thinking and behaving that may be relatively unused or in some cases unformed. Active support from staff, mentors, and fellow students are thus an essential feature of the program, while changing expectancies and behaviours bring about changes in the emotional colouring of a new set of personal experiences. 
Changes to these affective experiences are part of a larger change in outlook that can follow from changes in behaviour, including broader changes in the ways people see themselves and the emotional evaluations they make of themselves. As Bandura put it:

If there is any characteristic that is distinctively human, it is the capability for reflective self-consciousness. This enables people to analyze their experiences and to think about their own thought processes. By reflecting on their varied experiences and on what they know, they can derive generic knowledge about themselves and the world around them. People not only gain understanding through reflection, they evaluate and alter their own thinking by this means. In verifying thought through self-reflective means, they monitor their ideas, act on them or predict occurrences from them, judge from the results the adequacy of their thoughts, and change them accordingly (Bandura, 1989, p. 58).

Self-reflection is prompted by the content and the style of Clemente Australia. In a way that a vocational training course, for example, may not, a humanities course stimulates reflection on the lives of others and on one's own life. Questions of meaning, value, and purpose are intrinsic to the study of the humanities and it is through these questions that personal retrospection and prospection are encouraged, but not in a wholly egocentric way. The questions arise out of social experience, albeit the vicarious experience of reading, and are negotiated within the social situation of formal and informal discussion in the program. In this way, self-reflection is necessarily social in character. Through prompted self-reflection, there is a tying together of the discrete accomplishments of the program -- changed expectancies, altered emotions, and emerging competencies and self-regulating strategies -- with the setting of new goals for the future, with respect to the program and the world beyond it.

These broader changes can be understood in terms of the personal narrative. The concept of personal narrative is not to be found explicitly in social cognitive theory, partly because it involves a level of integration beyond that of situated behaviour and the cognitions that it gives rise to. As the quotation cited earlier from Bandura with reference to self reflection makes clear, however, generic knowledge about oneself is a result of the process of reflection. Personal narratives are the stories that people tell themselves about themselves, that people develop and revise in the course of their experience (McAdams, 1997). It is an on-going process of construction and reconstruction from experience and reflection and one that some theorists see as crucial to the idea of personal identity. Giddens (1991), for example, has argued that "a person's identity is not to be found in behavior, nor-important though this is-in the reactions of others, but in the capacity to keep a particular narrative going" (p. 54). As McAdams and Pals (2006, p. 209) put it: 
Narrative identity is indeed that story the person tries to 'keep going'-an internalized and evolving narrative of the self that incorporates the reconstructed past and the imagined future into a more or less coherent whole in order to provide the person's life with some degree of unity, purpose, and meaning.

The personal narrative functions to provide a sense of understanding and control of the person's environment, of order in daily experience, and of hope for the future (Orbuch, 1997). This higher level of integration can be traced back to social cognitive theory in terms of the link between development of self efficacy and outcome expectancies on the one hand and an emerging sense of hope on the other. According to Snyder hope is a phenomenological experience of "elevated ... mental energy and pathways for goals" that is substantially enduring across time and situations (Snyder, 1995 , p. 355). Measures of hope, as Snyder conceives it, have been shown in longitudinal studies with adolescent samples in the United States and Australia to predict academic achievement, emotional well-being, and general life satisfaction (Ciarrochi, Heaven, \& Davies, 2007; Valle, Huebner, \& Suldo, 2006). In Snyder's formulation, hope involves will power to achieve one's goals and the sense that one has the ability to generate pathways to achieve them. He proposed that the will power aspect of his definition of hope corresponds to Bandura's concept of self-efficacy, whereas the pathways aspect corresponds to outcome expectations. Hope involves the interaction of these and is a broader concept than those it subsumes, which are specific to situations. Hope is a cross-situational outlook on life that is built from increments in self-efficacy and expanding outcome expectations through the medium of the personal narrative.

According to a social cognitive analysis, then, Clemente Australia creates the conditions under which thought, behaviour, and life circumstances can change in initially small ways that, when sustained, aggregate into a sense of personal agency that is reflected in the stories people construct about themselves and in their interactions with their physical and social environment. Stages in the process are outlined in Figure 4. The program of liberal arts education as noted earlier has certain characteristics that are conducive to changes in thought and behaviour. In experiencing these conditions there can be changes in the characteristic ways people respond to their social world. Expectancies and goal setting have been discussed but there are likely to be a range of such changes. People will, for example, develop competencies in thinking about the world more abstractly and analytically or in writing about it. They may develop new ways of managing their emotions, such as anxiety, anger, or depression, or their resources, such as time. Through self-reflection on these changes as they develop over time, people's personal narratives can change to be more elaborated and more positive. All these changes, small and large, contribute to changes in action such as improved social networks, greater mastery of the environment, and to a greater sense of autonomy. 
1.Structured 2.Changes in Cognitions 3.Personal Narratives 4.Outcomes Environment \& Behaviour

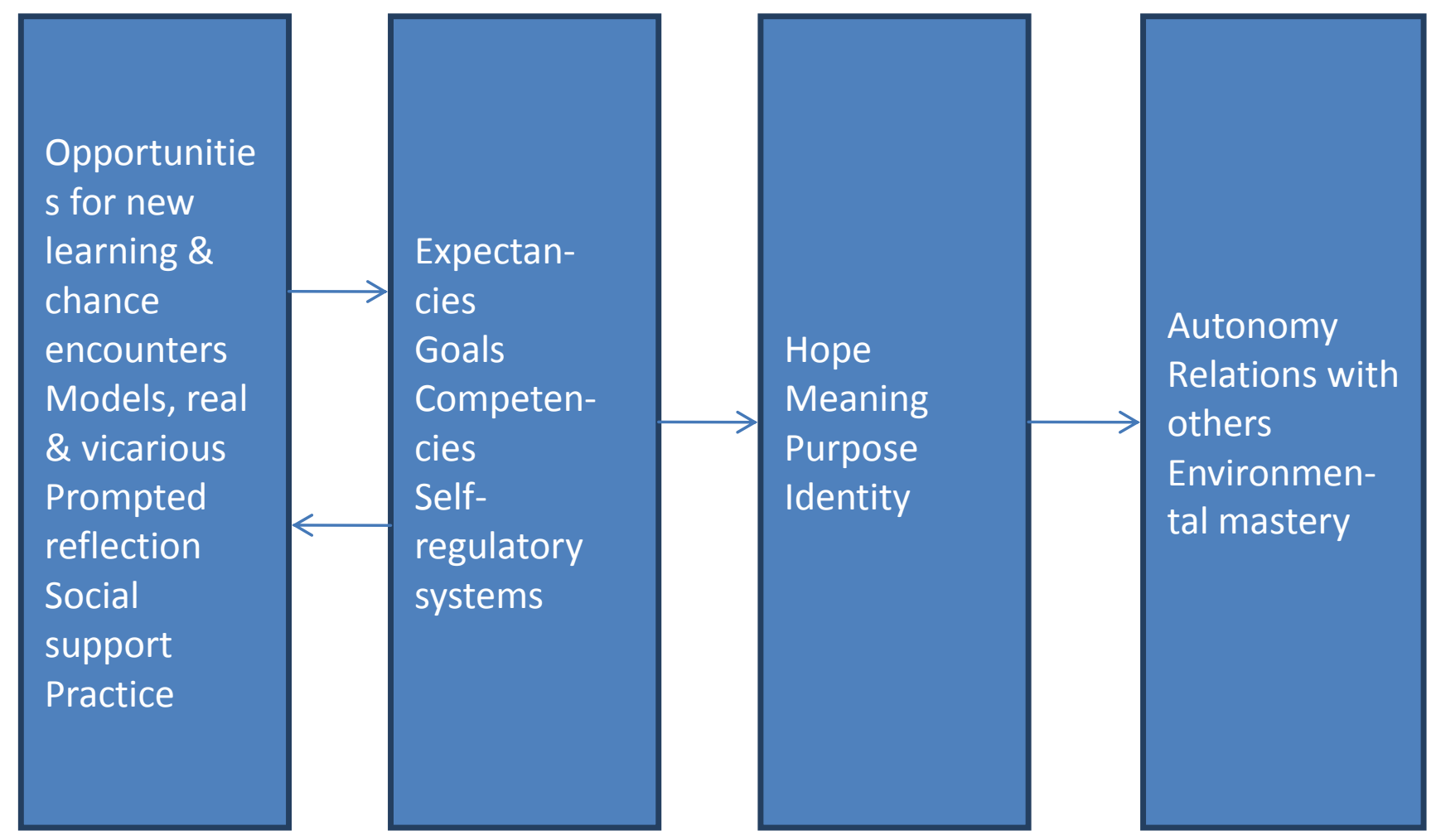

Figure 4. Stages in promoting agency through Clemente Australia

\section{Discussion}

The analysis advanced here in terms of social cognitive theory is a more detailed analysis of what may be going on in the course of Clemente Australia than offered in previous rationales of the program. It does not replace them but seeks to integrate them. That is, previous ideas of empowerment and engagement, of overcoming social exclusion, of interrupting habitus can all be seen through the lens of developing personal agency in social cognitive terms. Concepts of goal setting, self-efficacy and competencies, for example, are central to the model of empowerment advanced by Cattaneo and Chapman (2010), although in their model these have a specific reference to altering the power relations within a given social context. Shorris (1997b, p. 60) pointed out that the end of the process begun by Clemente may be political change but may be 'only' an improvement in the participants' social condition:

But coming into possession of the faculty of reflection and the skills of politics leads to a choice for the poor -- and whatever they choose, they will be dangerous: they may use politics to get along in a society based on the game, to 
escape from the surround of force into a gentler life, to behave as citizens, and nothing more; or they may choose to oppose the game itself". Put another way, Clemente Australia moves the participant to engagement but the transition from engagement to empowerment requires a further set of conditions or decisions.

So too, changing "socialised embodied perceptions, thoughts and actions", which in the analysis of Clemente Australia by Stevenson et al. (2007) is basic to the program, can be read in terms of social cognitive theory as changing beliefs, expectancies, and patterns of behaving in social contexts.

The account in terms of hope and personal agency advanced by Howard, Butcher, and Egan (2010) is closest to the model proposed here and indeed overlaps it. The difference lies in a greater specificity in the present model, both in terms of the link from the structure of the program (Panel 1 in Figure 4) to the participants' changed world views such as an increased sense of hope (Panel 3) and in terms of the situational versus global reach of the cognitions occurring at the levels described in Panels 2 and 3. Hope in the sense of a broad outlook on life, in the model outlined here, is not a simple outcome of the structures of Clemente Australia but the result of those structures facilitating the development of goal setting, efficacy, and outcome expectancies in a number of specific situations and of the participants' reflection on outcomes in those situations. Thus completion of a subject can increase outcome and efficacy expectancies in the limited domain of academic achievement but when aggregated with other achievements (e.g., sustained personal relations with staff or fellow students) can begin to develop the broader theme of hope in the individual narrative. It is the gradual and cumulative process of building from specific expectancies, goals, competencies, and self-regulatory systems to an elaborated life narrative of hope, meaning, and purpose that is critical to the program, encouraging the specific in order to achieve the general.

As John's story briefly outlined earlier (see Figure 1) makes clear, Clemente Australia provided structure to his life and contact with interesting ideas as well as a supportive group of staff and students (Panel 1 in Figure 4). As the program progressed, John developed a sense of his abilities and skills and beliefs about what was possible now and in the future (Panel 2). He had a developing sense of self esteem, that he was not 'a bum', that he was not 'on the dole' (government unemployment benefit) but had a meaningful place in the society as student and subsequently as volunteer and then paid employee (Panel 3). He developed a social network that was a resource as well as a support (Panel 4). John's account in no sense 'validates' the model in Figure 4 but shows how a map of the inputs, processes, and outputs of Clemente Australia in social cognitive theory terms can help illuminate personal experience of it.

One of the limitations of Figure 4, and of the brief case history of John, is that it presents the process in a simple linear model, whereas there is likely to be considerable iteration involved. The development of changes in behaviour and cognition under the influence of a structured program such as Clemente Australia takes time and repetition, with the continuing possibility for error and the need to loop round to establish real gains. 
Do these 'translations' of existing accounts help or is this just an exercise in theoretical imperialism? To communicate the processes of Clemente Australia to those involved in it and to those who might wish to be involved requires a language with sufficient depth and richness to accommodate the complexities of change in individuals and groups but at the same time one that is sufficiently straightforward as to be understandable by the non-professional. All theoretical viewpoints have their particular ranges of convenience and to some extent are incommensurable, but a framework such as the one proposed here that draws on social cognitive theory can bring at least some of the insights of existing rationales into an integrative account that can be worked with by participants. If personal agency is to have meaning, participants must be architects of their own change process but they need more than exposure to the structures of the program and exhortations to become engaged or empowered. Participants, staff, and learning partners in the program need to articulate how exposure can lead to significant change and need to become more deliberate about what they are doing and what might be at work when success is not achieved. The social cognitive framework provides a working model of the change process. Importantly, it can guide evaluation of the program by identifying the changes that should be taking place if the analysis is correct. Self-efficacy, outcome expectations, and goal setting are central concepts and measures of them should show changes over time. In the same way changes in personal narratives should occur and be linked to the changes in goal setting, efficacy, and outcome expectations. And changes in all these processes should be associated with changed outcomes for participants. Future evaluations of Clemente Australia can use this framework for a more fine-grain analysis of outcomes.

\section{Conclusion}

Clemente has been in existence for more than 10 years and is operating at many sites worldwide and across Australia as Clemente Australia, with perceived benefits to participants and the communities of which they are members. The benefits for the participants themselves include a higher level of personal agency and increases in capacities for social inclusion. The program has been theorised about in several ways since Shorris' initial thinking about the civilising effect of the humanities and the need to extend their study to the marginalised and disadvantaged as much as to the privileged in our society. Developing and expanding personal agency is seen as fundamental to the success of the program in many of the more recent accounts. The present integrative view refashions a rationale for the program in terms of social cognitive theory in which expectations and goal setting in the context of the structure of the program can lead through self-reflection to broader changes in the participant's understanding of the world in terms of hope, identity, meaning, and purpose. 


\section{References}

Apple, M. W. (1995). Education and power. 2nd ed. London: Routledge.

Bandura, A. (1977). Self-efficacy: Toward a unifying theory of behavioral change. Psychological Review, 84, 191-215.

Bandura, A. (1987). Social foundations of thought and action: A social cognitive theory, Englewood Cliffs, NJ: Prentice Hall.

Bandura, A. (1989). Social cognitive theory. In R. Vasta (Ed.), Annals of Child Development, Vol. 6. (pp. 1-60). Greenwich, CT: JAI.

Bandura, A. (1991). Self-regulation of motivation through anticipatory and self-reactive mechanisms. In R. A. Dienstbier (Ed.), Perspectives on motivation. Nebraska Symposium on Motivation. Vol. 38. (pp. 69-164). Lincoln, NB: University of Nebraska Press.

Bandura, A. ( 2006). Toward a psychology of human agency. Perspectives on Psychological Science, 1,164-180.

Barker, W. About the Clemente program. (2006). Halifax Chronicle Herald, 25 June.

Retrieved from http://stephenkimber.com/kings/about-the-clemente-program, 23 Nov 2010.

Becker, G. (1964). Human capital. New York, NY: National Bureau of Economic Research.

Broadbent, C. (2008). Engaging the disengaged through Clemente Australia. Annual National Conference of Audult Learning Australia, Fremantle, Western Australia.

Cattaneo, L. B., \& Chapman, A. R. (2010). The process of empowerment: A model for research and practice. American Psychologist, 65(7), 646-659.

Centre for the Study of Higher Education. (2008). Participation and equity: a review of the participation in higher education of people from low socioeconomic backgrounds and Indigenous people. University of Melbourne. Retrieved from http://www.universitiesaustralia.edu.au/resources/271/290 12 April 2012

Ciarrochi, J., Heaven, P. C. L., \& Davies, F. (2007). The impact of hope, self-esteem, and attributional style on adolescents' school grades and emotional well-being: A longitudinal study. Journal of Research in Personality, 41, 1161-1178.

Coleman, J. S. (1988). Social capital in the creation of human capital. American Journal of Sociology, 94, S95-S120.

DeCoker, G. (2002). Humanities for all: A review of Shorris's "Riches for All". The English Journal, 91(5), 92-94.

Egan, L. A., Butcher, J., Howard, P., Hampshire, A., Henson, C., \& Homel, R. (2006). The impact of tertiary-level humanities education for homeless and marginalised people. Paper presented at the Australian Association for Research in Education Conference, Adelaide, November [available: http://www.aare.edu.au/06pap/ega06635.pdf].

Endres, B. (2002). Critical pedagogy and liberal education: Reconciling tradition, critique, and democracy. Philosophy of Education. Retrieved from http://www.ed.uiuc.edu/EPS/PES-Yearbook/2002/59-endres\%2002.pdf 22 Sep 2011.

Giddens, A. (1991). Modernity and self-identity: Self and society in the late modern age, Stanford, CA; Stanford University Press.

Giroux, H. A., \& McLaren, P. L. (Eds.). (1989). Critical pedagogy, the state and cultural struggle. Albany, NY: State University of New York Press.

Hammond, C. (2004). Impacts of lifelong learning upon emotional resilience, psychological and mental health: fieldwork evidence. Oxford Review of Education, 30(4), 551-568.

Hayes, A., Gray, M., \& Edwards, B. (2008). Social Inclusion: Origins, Concepts and Key Themes. Department of Prime Minister and Cabinet, Social Inclusion Unit. 
Henry, K. (2007). Addressing extreme disadvantage through investment in capability development. Keynote address to Australian institute of Health and welfare conference, Canberra, December.

Howard, P., Butcher, J., \& Egan, L. (2010). Transformative education: Pathways to identity, independence and hope. International Journal of Community Research and Engagement, 3, 88-103.

Howard, P., Marchant, T., Hampshire, A., Butcher, P., Egan, L., \& Bredhauer, K. (2008). Promoting social inclusion: emerging evidence from the Clemente Australia program. $\quad$ Australian Journal of Adult Learning, 48(3), 479-501.

Lent, R. W., Brown, S. D., \& Hackett, G. (1994). Toward a unifying social cognitive theory of career and academic interest, choice, and performance. Journal of Vocational Behavior, 45, 79-122.

Locke, E. A., \& Latham G. P, (1990). A theory of goal setting and task performance. Englewood Cliffs, NJ: Prentice Hall.

McAdams, D. P. (1997). Stories we live by: Personal myths and the making of the self. New York, NY: Guilford Press.

McAdams, D. P., \& Pals, J. L. (2006). A new Big-Five: Fundamental principles for an integrative science of personality. American Psychologist, 61(3), 204-217.

Mission Australia. (2007). Enhancing participation: New possibilities for disadvantaged Australians, Author. Retrieved http://www.missionaustralia.com.au/downloads/social-policyreports/documents/file/216-enhancing-participation-new-possibilities-fordisadvantaged-australians?start=20 12 April 2012.

Orbuch, T. L. (1997). People's accounts count: The sociology of accounts. Annual Review of Sociology, 23, 455-478.

Perkins, D. D., \& Zimmerman, M. A. (1995). Empowerment theory, research, and applications. American Journal of Community Psychology, 23(5), 569-579.

Rothman, A. J., Baldwin, A. S., \& Hertel, A. W. (2004). Self-regulation and behavior change disentangling behavioural initiation and behavioral maintenance. In R. F. Baumeister, \& K. D. Vohs (Eds.). Handbook of Self-regulation: Research, theory, and application. (pp. 130-148). New York, NY: Guilford Press.

Shorris, E. (1997a). New American blues: A journey through poverty to democracy. New York, NY: Norton.

Shorris, E. (1997b). On the uses of a liberal education. Harpers Magazine, 9 January, 295(1768).

Shorris, E. (2000) Riches for the poor: The Clemente course in the humanities. New York, NY: Norton.

Stevenson, J., Yashin-Shaw, I., \& Howard, P. (2007). Reclaiming bodily dispositions through the humanities: homeless people learning. Journal of Vocational Education and Training, 59(4), 419-434.

Snyder, C. R. (1995). Conceptualizing, measuring, and nurturing hope. Journal of Counseling and Development, 73, 355-360.

Snyder, C. R., Ilardi, S. S., Cheavens, J., Michael, S. T., Yamhure, L., \& Sympson, S. (2000). The role of hope in cognitive-behavior therapies. Cognitive Therapy and Research, 24(6), 747-762.

Valle, M. F., Huebner, E. S., \& Suldo, S. M. (2006), An analysis of hope as a psychological strength. Journal of School Psychology, 44, 393-406.

Wood, R, \& Bandura, A. (1989). Social cognitive theory of organisational management. Academy of Management Review, 14(3), 361-384.

Yashin-Shaw, I., Howard, P., \& Butcher, J. (2005). Educating disaffected adult learners: Reengaging the homeless through tertiary level humanities studies. In: Vocational Learning: Transitions, Interrelationships, Partners and Sustainable 
Futures', Proceedings of the 13th Annual International Conference on PostCompulsory Education and Training, Brisbane, Australian Academic Press.

\section{Biographical Notes}

John O'Gorman is an Adjunct Professor in the School of Applied Psychology and the Behavioural Basis of Health Program at Griffith University. His interests include processes of individual and organizational change.

Jude Butcher cfc, AM, is Professor and Director of the Institute for Advancing Community Engagement (IACE) at Australian Catholic University. Jude has developed within the Institute and the University an agenda of hope with communities focusing upon moving together beyond disadvantage to more equitable and inclusive societies. His community engagement and research are in the areas of community engagement and higher education, educational capacity building and transformational partnerships. $\mathrm{He}$ has been involved in capacity building in Timor Leste for more than 11 years. He has also been part of the University's Aboriginal education programs for more than 25 years. In 2010 he was appointed a Member (AM) in the Order of Australia for service to teacher education, particularly in the Catholic sector, and to the community through contributions to social justice

Peter Howard is an Associate Professor of the Institute for Advancing Community Engagement (IACE) at Australian Catholic University. Peter is the National Leader for Clemente Australia with the program beginning in Australia in 2003. In the context of this program Peter researches community based learning with people experiencing homelessness and disadvantage. Peter is also IACE's National Leader for Beyond Disadvantage working with communities and the University in developing community based approaches to equity and social inclusion. Peter has also investigated issues about effective collaboration in Aboriginal education and mathematics education for the past 25 years. His research focuses on the mathematical beliefs of Aboriginal people, the building of community capacity and the influence of socio-cultural elements upon the learning of marginalised peoples. He has been involved in evaluating the effectiveness of a number of mathematics education programs with a focus on enhancing Aboriginal student's learning. 